\title{
The Role of Trait Emotional Intelligence in Individual Performance: A Descriptive Study in Albaha University, Saudi Arabia
}

\author{
Faris S. Alghamdi \\ Faculty of Financial and Administrative Sciences, Albaha University, Albaha, Saudi Arabia \\ Email: fsaleh@bu.edu.sa
}

Received 31 August 2014; revised 26 September 2014; accepted 18 October 2014

Copyright (C) 2014 by author and Scientific Research Publishing Inc.

This work is licensed under the Creative Commons Attribution International License (CC BY). http://creativecommons.org/licenses/by/4.0/

c) (i) Open Access

\begin{abstract}
The current study investigates the relationship between emotional intelligence and individual performance, namely academic performance. It also aims at determining whether emotional intelligence differs between male and female students. The data were obtained through the Schutte Self-Report Emotional Intelligence (SSREI) questionnaire, which was distributed to undergraduate students in Albaha province, Saudi Arabia. A sample of 191 undergraduate students filled in (SSREI), which included the demographic and academic performance measures. The results indicated that the relationship between emotional intelligence and academic performance was not statistically significant. Moreover, no statistically significant difference was found between male and female students in the total of emotional intelligence score.
\end{abstract}

\section{Keywords}

\section{Emotional Intelligence, Individual Performance, Academic Performance}

\section{Introduction}

Prevalent opinion and work-place testimonials claimed that emotional intelligence (EI) influences individual performance [1]. [2] pointed out that EI may be the best predictor of success in life, redefining what it means to be smart. Likewise, [3] stated that EI can predict success at home, at work, at school, and in relationships, as well as or better than intelligence quotient (IQ). The ultimate root of EI can be traced back to the concept of "social intelligence" developed by [4] who believed that humans possess many types of intelligence. The term social intelligence denotes to the ability to understand and manage people and to act wisely in relationships with others. The proximal root of EI stemmed from the work of [5] in his concept of intrapersonal and interpersonal 
intelligence [6]. The present form of EI was introduced in 1990 [7] to represent the ability to deal with emotions, and was driven into prominence by [5] best-selling book, following by a lead article in TIME magazine [2]. This study attempts to examine the relationship between emotional intelligence and an individual performance, students' GPA, and to determine whether there is a difference between male and female students in their emotional intelligence scores, presenting through four dimensions.

\subsection{Emotional Intelligence}

The question of what is EI has no simple answer, because it has been defined in many ways. For example, [8] defined EI as a cognitive, that is, the ability to comprehend and reason about emotions. Others defined it more broadly. [5] added some personality variables (i.e., persistence and optimism, to the definition. [9] defined EI as the trend to make decisions in accordance with feelings instead of rationality, and/or the trend to express one's emotions nonverbally. It should be noted that the concept of EI is overlapping with other constructs, namely, social intelligence (the ability to understand others and act wisely in social circumstances), empathy (the ability to understand others' feelings and the trend to experience others' emotions vicariously), and alexithymia (difficulty to understand to describe feelings), and emotion regulation (the ability to regulate ones' emotions as desired). Surprisingly, the tests that were initially applied to measures these four constructs are currently often applied to measure EI [10]. Moreover, each theoretical paradigm conceptualizes EI from one of three perspectives, namely ability, mixed model, or trait. Ability models consider EI a pure form of mental ability and hence a pure intelligence, whereas mixed models combine mental ability with personality characteristics such as optimism and well-being. These models conceptualize EI as a combination of cognitive, motivational, and affective constructs, and hence they claim that EI is not a type of intelligence (e.g., spatial ability) due to the combining of intellective and non-ability traits. Finally, trait models regard EI as a non-cognitive capability [11] [12]. The most appropriate method of measuring EI is now an area of controversy. Trait EI is measured using self-report questionnaires and links to the realm of personality, whereas ability EI needs the use of maximum-performance tests with correct and incorrect answers and links largely to the realm of cognitive ability.

\subsection{Individual Performance}

Performance in a given situation can be seen as "resulting from the interrelationships among effort, abilities, and role perceptions [13]”. Effort, as a result of motivation, indicates to the amount of energy expended (physical and/or mental) individuals utilize to perform a task, whereas abilities refer to personal characteristics used in performing a task; it is not usually fluctuating widely over short periods of time. Role (task) perceptions denote to a direction wherein individuals believe they should channel their effort on their tasks. The activities and behaviors individuals believe are needed in performing their tasks define their role perceptions.

[14] pointed out that the psychology of individual differences came in attempts to forecast scholastic performance. They claimed that performance of university students at undergraduate level is usually expressed in terms of grade point average (GPA). It is an index of performance directly pertinent to training an employment opportunities and is meaningful to students, universities, and employers alike. In sum, GPA is an objective measure with good internal reliability and temporal stability, and therefore no other academic performance competes for the measurement utility of it [15]. In the current study, the GPA was measured using four categories, that is, less than $2,2-2.9,3-3.4$, and $3.5-4$.

\subsection{Emotional Intelligence and Academic Performance}

Many theorists have claimed that EI predicts individual performance in a verity of settings, beyond the influence of established predictors such as general mental ability and personality. Nevertheless, empirical studies of the association between EI and performance have resulted in inconsistent results. So far, close examination of conducted studies regarding EI shows at least four factors that may be limiting our ability to get meaningful conclusions from the data produced. The first two factors are methodological in nature, whereas the second two factors deal with the possible presence of boundary conditions on the EI performance relationship [16].

Regarding the first two factors, the measurement of EI is widely different across studies. For instance, [17] [10], and [18] applied the "mental abilities" model of EI [19]-[21] through corresponding problem-based measure of the construct. On the other hand, some researchers utilized broader "mixed" or "trait" models of EI through different self-report measure. Having Clearfield that, given research indicating that self-report and per- 
formance-based measures of EI take part in a relatively small amount of variance $(r=0.15$ to 0.31$)$. As a result, many authors conclude that they tap into different constructs [22].

Several distinguished self-report measures of EI have been criticized for lacking discriminant validity from measure of personality [23] [24]. Findings from earlier studies show variation, depending on the control variables that were included in the research models. In the academic realm, some researchers have found a relationship between EI and individual performance (GPA; [6] [16] [17] [25]; however, other researchers have found no significant relationship between these two variables after controlling for general mental ability and personality [10] [26]. [16] claimed that researchers have not carefully taken into account the description and comparison of different types of individual performance that may be related to EI, although performance is known to be a multidimensional construct. A study by [11] found that male students had a higher emotional intelligence score than female students. This finding is the opposite of some previous studies where female students have repetitively had higher emotional intelligence scores than male students [8] [12] [27]-[29]. From the discussion above, the following hypotheses are proposed:

Hypothesis H1: Emotional intelligence is positively associated with academic performance, as measure by student GPA.

Hypothesis H2: Female students will have higher emotional intelligence scores than male students, presenting through four dimensions.

\section{Methodology}

\subsection{Sample}

The target population of this study consisted of all students at an undergraduate level in Albaha province, Saudi Arabia. All of the students had graduated from high school within the past 2 years and were in their first-year of full-time study. In maintaining confidentiality for all participants, the informed consent was obtained from all participants before the process of collecting the data; and the anonymity of all participants was preserved as well. A cover letter providing some information about the importance of the study, participants' rights, as well as explaining how to respond to the questionnaire items was attached. The sample of the study was selected using the convenience sampling technique. There were 223 questionnaires distributed to participants who met the criteria mentioned above. Trained employees worked with the researcher have been assigned to distribute the questionnaires to potential subjects and then collect all questionnaires that have been filled. Of distributed questionnaires, 191 were returned and useful for analysis, with response rate of $86 \%$.

\subsection{Instrument}

The current study applied a descriptive cross-sectional method. The Schutte Self-Report Emotional Intelligence (SSREI) scale by [28] modified by [30] was used to measure the trait EI of all participants in the current study. The SREIS has been designed to map onto the [7] model of EI. The modification questionnaire comprised of 21, 5-poit Likert scale items, three of which are negatively keyed. It includes four dimensions: appraisal of emotions in the self (AES; 2 items), appraisal of emotions in others (AEO; 7 items), emotional regulation of the self (ERS; 8 items), and utilization of emotions in problem solving (UEPS; 4 items). The response was recorded on a fivepoint scale wherein " 1 " indicates "strongly disagree" and " 5 " indicates "strongly agree". The modified questionnaire was translated from English language to Arabic language, which is the official language for all potential participants, using a back-translation technique. In doing so, a professor at Albaha University translated the modified questionnaire into Arabic language and then another professor at the same university translated back to English language without references to the original English version. Both professors are fully bilingual. After that, the researcher went carefully over both versions and made revisions needed in order to ensure a complete and accurate meaning of the original text of the modified questionnaire. In addition to that, the researcher wanted to ensure that an appropriate level of formality for all potential participants can be achieved.

\section{Data Analysis}

Descriptive statistics were used to summarize data. The current study utilized Pearson correlation test to examine the relationship between emotional intelligence and academic performance. Mann-Whitney U test was used to determine if there is a statistically significant difference in emotional intelligence between male and fe- 
male students, presenting through four dimensions. All statistical analyses were conducted using SPSS for Windows (version 19.0, 2010, Chicago, IL). Statistical significance at $P \leq 0.05$ was used for all tests.

\section{Results}

The study sample was composed of $63.4 \%$ (121) male and 36.6\% (70) female. Of the sample, $20.4 \%$ (39) of the students were from the medical track, $45 \%$ (86) of the students were from the science track, and $34.6 \%$ (66) of the students were from the art track. As to the GPA, 5.8\% (11) of the students were less than 2, 31.4\% (60) of the students were between 2 - 2.9, 25.1\% (48) of the students were between 3 - 3.4, and 37.7\% (72) of the students were between 3.5 - 4. The age of all participants was between 18 and 23 years old. In this study, the females' overall emotional intelligence score was slightly higher than that of males. That is, the male students had a mean score of $4.20(\mathrm{SD}=0.58)$ for the use of appraisal of emotions in the self, whereas female students had a mean score of 4.15 ( $\mathrm{SD}=0.52$ ) in using of the same dimension of emotional intelligence. As to the use of appraisal of emotions in others, male students had a mean score of $3.29(\mathrm{SD}=0.40)$, whereas their counterparts had a mean score of $3.33(\mathrm{SD}=0.45)$. In terms of emotional regulation of the self, male students had a mean score of 3.90 ( $S D=0.41$ ), whereas female students had a mean score of $3.94(S D=0.42)$. Finally, male students reported a mean score of $4.06(\mathrm{SD}=0.54)$ in the use of utilization of emotions in problem solving, while female students reported a mean score of $4.05(\mathrm{SD}=0.44)$.

To test the first hypothesis, the Pearson correlation test was used. As shown in Table 1 , the $P$ values for all four dimensions of emotional intelligence were above the statistical significance set for the purpose of the current study. Therefore, the first study hypothesis was not supported.

To test the second study hypothesis, the Mann-Whitney U test was applied. As shown in Table 2, the $P$ value was above the statistical significance set for the purpose of the current study. Hence, the second study hypothesis was not supported.

\section{Discussion}

The present study aimed at investigating the relationship between emotional intelligence and an individual performance through academic performance. It examined potential difference between male and female students in means on emotional intelligence. Evaluation of correlational test revealed that contrary to studies indicating a significant relationship between emotional intelligence and academic performance as measured by grade point average [3] [6] [16] [25] [26] [31]-[33], the current study did not find a significant association between emotional intelligence and academic performance [10] [27]. Nor was there difference between male and female students in means on emotional intelligence. This finding is in line with some previous studies [34]-[37].

The results of this study can be explained by some possible sources. First, to the best of my knowledge, in Saudi Arabia, because emotional intelligence is a relatively new skill to be learned and developed and very little information is known about it, incorporating this important skill into first year curriculum seems to be a risky

Table 1. The correlation between EI and academic performance.

\begin{tabular}{cccccccc}
\hline & & GPA & AES & AEO & ERS & UEPS \\
\hline \multirow{3}{*}{ GPA } & Pearson Correlation & 1 & -0.023 & -0.031 & -0.032 & -0.063 \\
& Sig. (1-Tailed) & & 0.377 & 0.337 & 0.329 & 0.193 \\
& $\mathrm{~N}$ & 191 & 191 & 191 & 191 & 191 \\
\hline
\end{tabular}

Table 2. The difference in EI between male and female.

\begin{tabular}{|c|c|c|c|c|}
\hline \multicolumn{5}{|c|}{ Test Statistics $^{\mathrm{a}}$} \\
\hline & AES & AEO & ERS & UEPS \\
\hline Mann-Whitney U & 3878.000 & 3868.000 & 3966.500 & 4173.500 \\
\hline Wilcoxon W & 6363.000 & $11,249.000$ & $11,347.500$ & 6658.500 \\
\hline $\mathrm{Z}$ & -1.011 & -1.004 & -0.733 & -0.169 \\
\hline Asymp. Sig. (2-Tailed) & 0.312 & 0.316 & 0.464 & 0.866 \\
\hline
\end{tabular}

a: Grouping Variable: SEX. 
decision. [31] conducted an experimental study to analyze the effects of emotional intelligence training on academic performance. Five groups of graduate-level management students completed pre and post emotional intelligence questionnaires. One of the five groups received emotional intelligence instruction during their courses, while the other four groups received no formal or informal emotional intelligence instruction or discussion. With beginning level of knowledge and teaching effectiveness controlled for, final grades were used to evaluate student academic performance. He concluded that the group receiving the emotional intelligence curriculum significantly increased their emotional intelligence quotient scores and performed better academically than the four groups of students who did not receive such training. Applying to our sample, students lack awareness of their soft skills, i.e. emotional intelligence, would respond to the given questionnaire blurredly, which in turn, leading to an unexpected results.

Second, as [10] pointed out, if a large number of emotional intelligence measures are applied without preselecting, these measures would not predict academic performance. He concluded that cognitive ability and the personality domain do a far better job predicting academic performance. By the same token, since the study sample was selected from undergraduate students in their first semester at the university, it is not surprisingly that the transition from high school to university is perceived by most students as a particularly stressful situation. In the present study, emotional intelligence dimensions do not include adaptability and stress management abilities which are important factors in predicting academic performance [33]. Finally, the current study applied the Schutte Self-Report Emotional Intelligence (SSREI) that was developed in Western culture (i.e., individualism vs. collectivism). This instrument might not be suitable tool in non-Western culture, contributing to these unexpected results.

\section{Limitations and Future Research Directions}

As interpreting the results in this study, the following limitations should be taken into account, which in turn, would provide avenues for future research. First, the study results were driven from small sample size and hence future studies may select lager sample size. Second, the design of the study is cross sectional, which is a snapshot of the situation, and hence future studies can avoid that by taking longitudinal samples. The study sample was selected from students in their first semester; however, future samples can be taken from students at different levels of study. The questionnaire, applied in this study, was developed and used in Western culture, which might not be appropriate to be applied to subjects from different culture background. Therefore, future studies may consider modifying the current instrument or developing another one in order to be used in non-Western culture. Finally, this study used the non-random sampling technique, convenience sampling, which may limit the ability to generalize our results. Consequently, future studies should apply the random sampling technique instead.

\section{Conclusion}

This is the first known study conducted in Albaha province to examine the role of trait emotional intelligence in academic performance of undergraduate students. It makes several important contributions to the growing body of knowledge surrounding emotional intelligence. This study implies that despite the fact that emotional intelligence was not correlated with academic performance, it is recommended that emotional intelligence skills should be introduced first to students who are studying in some developing countries where paying adequate attention to special soft skills during academic years is rare. As such, awareness of emotional intelligence for students should be prior to any attempt to measure such skill. Students produce their own EI profiles and the useful "tips for development" workbook whereby students can take some control in their own development of skills for which they perceive themselves to be weak. Moreover, this study recommends that educational planners and policy makers should include EI developing courses that should be taught by experts of the field at university level, starting in the first semester of study.

\section{Acknowledgements}

This research is a part of a project entitled "The role of Trait Emotional Intelligence in Individual Performance: a Descriptive Study in Albaha University, Saudi Arabia”. This project was funded by the Deanship of Scientific Research, Albaha University, KSA (Grant No. 145-2014). The assistance of the Deanship is gratefully ac- 
knowledged.

\section{References}

[1] Lam, L. and Kirby, S. (2002) Is Emotional Intelligence an Advantage? An Exploration of the Impact of Emotional and General Intelligence on Individual Performance. The Journal of Social Psychology, 142, 133-143. http://dx.doi.org/10.1080/00224540209603891

[2] Gibbs, N. (1995) The EQ Factor. Time, 146, 60-68.

[3] Goleman, D. (1995) Emotional Intelligence. Bantan Books, New York.

[4] Thorndike, E. (1920) Intelligence and Its Uses. Harper's Magazine, 140, 227-235.

[5] Gardner, H. (1983) Fames of Mind: The Theory of Multiple Intelligence. Basic Books, New York.

[6] Petrides, K., Frederickson, N. and Furnham, A. (2004) The Role of Trait Emotional Intelligence in Academic Performance and Deviant Behavior at School. Personality and Individual Differences, 36, 277-293. http://dx.doi.org/10.1016/S0191-8869(03)00084-9

[7] Salovey, P. and Mayer, J. (1990) Emotional Intelligence. Imagination, Cognition, and Personality, 9, 185-211. http://dx.doi.org/10.2190/DUGG-P24E-52WK-6CDG

[8] Mayer, J., Caruso, D. and Salovey P. (1999) Emotional Intelligence Meets Traditional Standards for an Intelligence. Intelligence, 27, 267-298.

[9] Tett, R., Wang, A., Gribler, J. and Martinez, A. (1997) Development of Self-Report Measures of Emotional Intelligence. Paper Presented at the 1997 Annual Convention of the Southeastern Psychological Association, Atlanta, GA.

[10] Barchard, K. (2003) Dose Emotional Intelligence Assist in the Prediction of Academic Success? Educational \& Psychological Measurement, 63, 840-859. http://dx.doi.org/10.2190/DUGG-P24E-52WK-6CDG

[11] Shi, J. and Wang, L. (2007) Validation of Emotional Intelligence Scale in Chinese University Students. Personality and Individual Differences, 43, 377-387. http://dx.doi.org/10.1016/j.paid.2006.12.012

[12] Saklofske, D., Austin, E. and Minski, P. (2003) Factor Structure and Validity of a Trait Emotional Intelligence Measure. Personality and Individual Differences, 34, 707-721. http://dx.doi.org/10.1016/S0191-8869(02)00056-9

[13] Byars, L. and Rue, L. (2011) Human Resource Management. McGraw-Hill, New York.

[14] Richardson, M., Abraham, C. and Bond, R. (2012) Psychological Correlates of University Students’ Academic Performance: A Systematic Review and Meta-Analysis. Psychological Bulletin, 138, 353-387. http://dx.doi.org/10.1037/a0026838

[15] Plant, E., Ericsson, K., Hill, L. and Asberg, K. (2005) Why Study Time Does Not Predict Grade Point Average across College Students: Implications of Deliberate Practice for Academic Performance. Contemporary Educational Psychology, 30, 96-116. http://dx.doi.org/10.1016/j.cedpsych.2004.06.001

[16] Rode, J., Mooney, C., Arthaud-Day, M., Near, J., Baldwin, T., Rubin, R. and Bommer, W. (2007) Emotional Intelligence and Individual Performance: Evidence of Direct and Moderated Effects. Journal of Organizational Behavior, 28, 399-421. http://dx.doi.org/10.1002/job.429

[17] Brackett, M., Mayer, J. and Warner, R. (2004) Emotional Intelligence and Its Expression in Everyday Behavior. Personality and Individual Differences, 36, 1387-1402. http://dx.doi.org/10.1016/S0191-8869(03)00236-8

[18] O’Connor, R. and Little, I. (2003) Revising the Predictive Validity of Emotional Intelligence: Self-Report versus Ability-Based Measures. Personality and Individual Differences, 35, 1893-1902. http://dx.doi.org/10.1016/S0191-8869(03)00038-2

[19] Mayer, J., Salovey, P. and Caruso, D. (2000) Models of Emotional Intelligence. In: Sternberg, R., Ed., Handbook of Intelligence, Cambridge University Press, Cambridge, 396-420. http://dx.doi.org/10.1017/CBO9780511807947.019

[20] Mayer, J. and Salovey, P. (1993) The Intelligence of Emotional Intelligence. Intelligence, 17, 433-442. http://dx.doi.org/10.1016/0160-2896(93)90010-3

[21] Mayer, J. and Salovey, P. (1997) What Is Emotional Intelligence? In: Salovey, P. and Sluyter, D., Eds., Emotional Development and Emotional Intelligence: Educational Implications, Basic Books, New York, 3-31.

[22] Mayer, J., Salovey, P. and Caruso, D. (2004) Emotional Intelligence: Theory, Findings, and Implications. Psychological Inquiry, 15, 197-215. http://dx.doi.org/10.1207/s15327965pli1503 02

[23] Davies, M., Stankov, L. and Roberts, R. (1998) Emotional Intelligence: In Search of an Elusive Construct. Journal of Personality and Social Psychology, 75, 989-1015. http://dx.doi.org/10.1037/0022-3514.75.4.989

[24] MacCann, C., Roberts, R., Matthews, G. and Zeidner, M. (2003) Consensus Scoring and Empirical Option Weighting of Performance-Based Emotional Intelligence (EI) Tests. Personality and Individual Differences, 36, 645-662. 
http://dx.doi.org/10.1016/S0191-8869(03)00123-5

[25] Van Der Zee, K., Thijs, M. and Schakel, L. (2002) The Relationship of Emotional Intelligence with Academic Intelligence and the Big Five. European Journal of Personality, 15, 103-125. http://dx.doi.org/10.1002/per.434

[26] Newsome, S., Day, A. and Catano, V. (2000) Assessing the Predictive Validity of Emotional Intelligence. Personality and Individual Differences, 29, 1005-1116. http://dx.doi.org/10.1016/S0191-8869(99)00250-0

[27] Day, A. and Carroll, S. (2004) Using an Ability-Based Measure of Emotional Intelligence to Predict Individual Performance, Group Performance, and Group Citizenship Behaviors. Personality and Individual Differences, 36, 1443-1458. http://dx.doi.org/10.1016/S0191-8869(03)00240-X

[28] Schutte, N., Malouff, J., Hall, L., Haggerty, D., Cooper, J., Golden, C. and Dornheim, L. (1998) Development and Validation of a Measure of Emotional Intelligence. Personality and Individual Differences, 25, 167-177. http://dx.doi.org/10.1016/S0191-8869(98)00001-4

[29] Van Rooy, D., Alonso, A. and Viswesvaran, C. (2005) Group Differences in Emotional Intelligence Scores: Theoretical and Practical Implications. Personality and Individual Differences, 38, 689-700. http://dx.doi.org/10.1016/j.paid.2004.05.023

[30] Gignac, G., Palmer, B., Manocha, R. and Stough, C. (2005) An Examination of the Factor Structure of the Schutte Self-Report Emotional Intelligence (SSREI) Scale via Confirmatory Factor Analysis. Personality and Individual Differences, 39, 1029-1042. http://dx.doi.org/10.1016/j.paid.2005.03.014

[31] Jaeger, A. (2003) Job Competencies and the Curriculum: An Inquiry into Emotional Intelligence in Graduate Professional Education. Research in Higher Education, 44, 615-39. http://dx.doi.org/10.1023/A:1026119724265

[32] Drago, J. (2004) The Relationship between Emotional Intelligence and Academic Achievement in Nontraditional College Students. Unpublished Ph.D. Thesis, Walden University, Minneapolis.

[33] Parker, J., Duffy, J., Wood, L., Bond, B. and Hogan, M. (2005) Academic Achievement and Emotional Intelligence: Predicting the Successful Transition from High School to University. Journal of the First-Year Experience and Students in Transition, 17, 67-68.

[34] Bar-On, R. (2000) Emotional and Social Intelligence: Insights from the Emotional Quotient Inventory. In: Bar-On, R. and Parker, J.D.A., Eds., Handbook of Emotional Intelligence, Jossey-Bass, San Francisco, 363-388.

[35] Goleman, D. (1998) Working with Emotional Intelligence. Bantam Books, New York.

[36] Petrides, K. and Furnham, A. (2000) On the Dimensional Structure of Emotional Intelligence. Personality and Individual Differences, 29, 313-320. http://dx.doi.org/10.1016/S0191-8869(99)00195-6

[37] Whitman, D., Van Rooy, D., Viswesvaran, C. and Kraus, E. (2009) Testing the Second-Order Factor Structure and Measurement Equivalence of the Wong and Law Emotional Intelligence Scale across Gender and Ethnicity. Educational and Psychological Measurement, 69, 1059-1074. http://dx.doi.org/10.1177/0013164409344498 
Scientific Research Publishing (SCIRP) is one of the largest Open Access journal publishers. It is currently publishing more than 200 open access, online, peer-reviewed journals covering a wide range of academic disciplines. SCIRP serves the worldwide academic communities and contributes to the progress and application of science with its publication.

Other selected journals from SCIRP are listed as below. Submit your manuscript to us via either submit@scirp.org or Online Submission Portal.
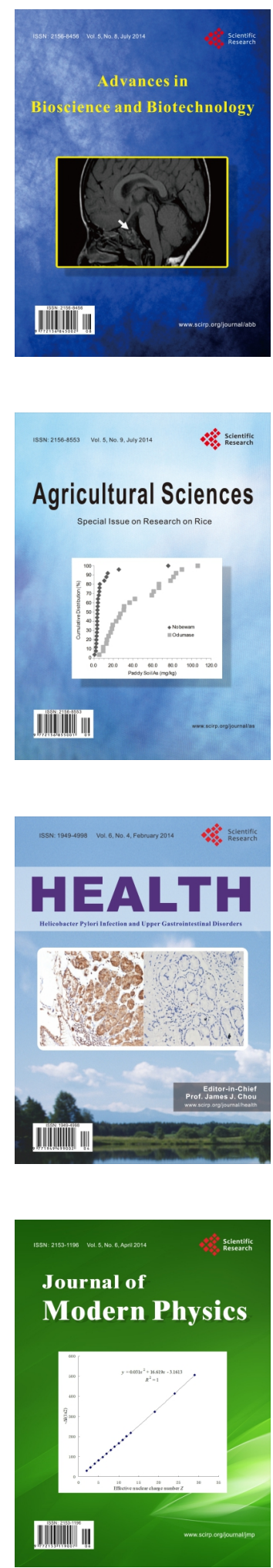
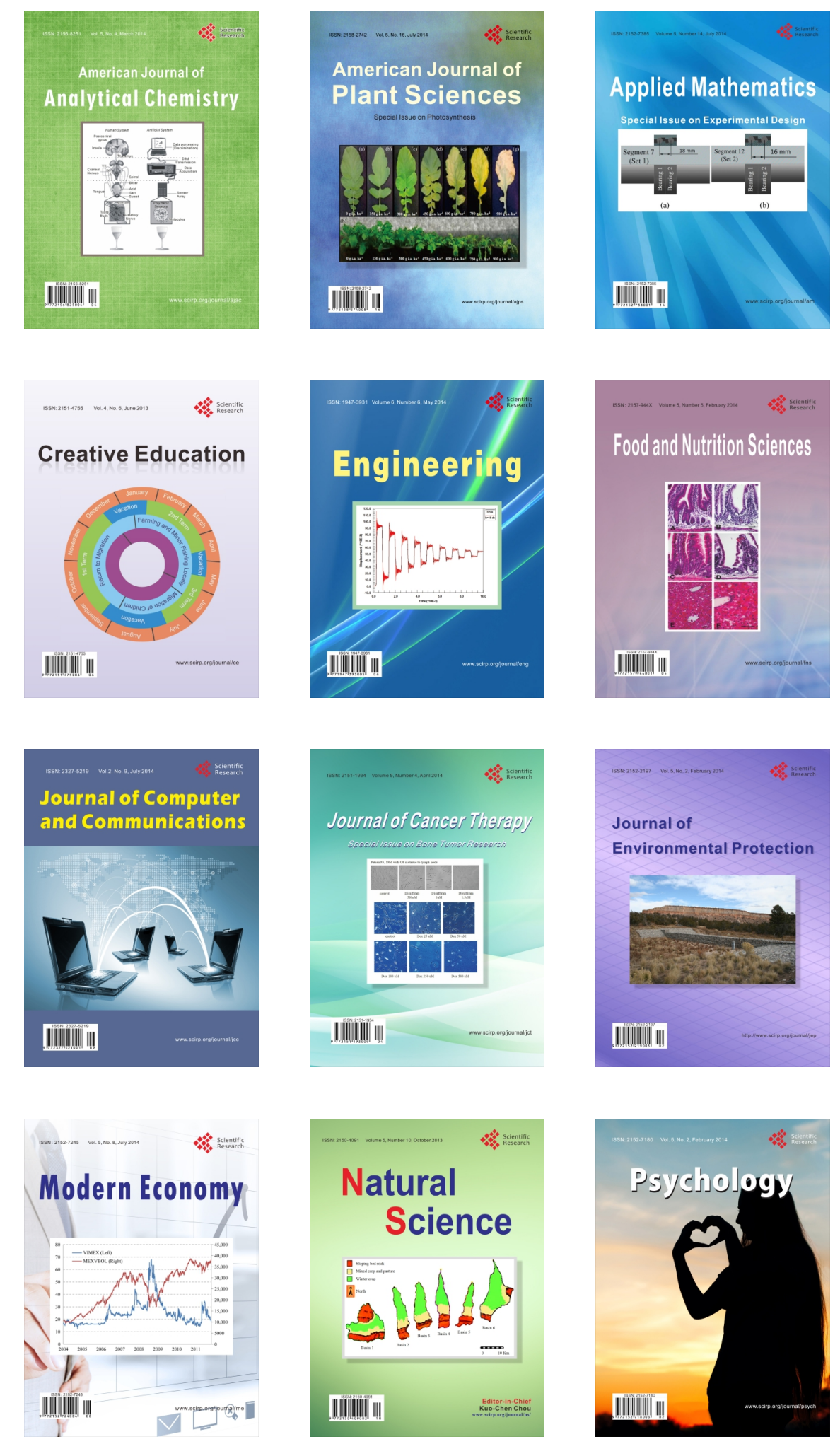